\title{
TECNOLOGIAS DIGITAIS DA INFORMAÇÃO E COMUNICAÇÃO NO ENSINO DE MATEMÁTICA EM TEMPOS DE PANDEMIA: DESAFIOS E POSSIBILIDADES
}

\section{DIGITAL TECHNOLOGIES OF INFORMATION AND COMMUNICATION IN THE TEACHING OF MATHEMATICS IN PANDEMIC TIMES: CHALLENGES AND POSSIBILITIES}

\author{
João Nazareno Pantoja Corrêa ${ }^{1}$; João Cláudio Brandemberg ${ }^{2}$
}

\begin{abstract}
RESUMO
Este trabalho aborda o uso das tecnologias digitais da informação e comunicação no ensino de Matemática durante a pandemia do coronavírus, desse modo, tem como objetivo apresentar algumas possibilidades de desenvolvimento de atividades educacionais, em especial o ensino de Matemática, tendo em vista a suspensão presencial destas, bem como alguns desafios existentes. Para tanto, apresenta a diferença entre ensino remoto e ensino a distância, e também entre Tecnologias, Tecnologias da Informação e Comunicação (TIC) e as Tecnologias Digitais da Informação e Comunicação (TDIC), buscando familiarizar o leitor com tais conceitos, em seguida relaciona as Tecnologias Digitais e a Formação de Professores de Matemática e, posteriormente, aborda a problemática da falta de equidade no ensino com a implementação de aulas remotas no Brasil. Neste contexto, indica possíveis alternativas para realização de atividades educacionais de maneira remota e para desenvolvimento de aulas por áudio e vídeo, apresentando o Google Classroom e plataformas como Zoom Meetings, Google Meet, Microsoft Teams, YouTube, Facebook Live e Instagram. Por meio do presente trabalho, inferimos que o uso de novas tecnologias, bem como a implementação do ensino e aprendizagem com o auxílio destas, com qualidade, requer planejamento e investimentos, os quais não serão possíveis em curtíssimo prazo, como tem ocorrido, por exemplo, nesse momento de pandemia, e ainda que os conhecimentos desenvolvidos com esses recursos possam ser utilizados potencialmente para fins educacionais de modo que alertamos para necessidade que o Brasil possui de incentivos à formação docente com novas propostas de integração e não de substituição do ensino presencial e/ou remoto com qualidade.
\end{abstract}

Palavras-chave: Tecnologias Digitais; Aulas Remotas; Pandemia; Ensino de Matemática.

\footnotetext{
${ }^{1}$ Mestrado em Ensino de Matemática pela Universidade do Estado do Pará (UFPA). Professor de Matemática vinculado à Secretaria de Estado de Educação do Pará (SEDUC-PA), Belém, Pará, Brasil. Endereço para correspondência: Rua Lauro Sodré, 168, centro, Igarapé-Miri, Pará, Brasil, CEP: 68430000. E-mail: joaonpcorrea@hotmail.com.

iD ORCID iD: https://orcid.org/0000-0002-1875-4711.

2 Doutorado em Educação pela Universidade Federal do Rio Grande do Norte (UFRN). Professor Associado III vinculado à Universidade Federal do Pará (UFPA), Belém, Pará, Brasil. Endereço para correspondência: Rua Augusto Corrêa, 01, Universidade Federal do Pará, Faculdade de Matemática ICEN, Guamá, Belém, Pará, Brasil, CEP: 66075-110. E-mail: brand@ufpa.br.

(iD) ORCID iD: https://orcid.org/0000-0001-8848-3550.
} 


\begin{abstract}
This work addresses the use of digital information and communication technologies in the teaching of Mathematics during the coronavirus pandemic, thus, it aims to present some possibilities for the development of educational activities, in particular the teaching of Mathematics, with a view to face-to-face suspension of these, as well as some existing challenges. Therefore, it presents the difference between remote and distance learning, and also between Technologies, Information and Communication Technologies (ICT) and Digital Information and Communication Technologies (DICT), seeking to familiarize the reader with such concepts, then Digital Technologies and the Training of Mathematics Teachers and, later, addresses the problem of lack of equity in teaching with the implementation of remote classes in Brazil. In this context, it indicates possible alternatives for conducting educational activities remotely and for developing audio and video classes, featuring Google Classroom and platforms such as Zoom Meetings, Google Meet, Microsoft Teams, YouTube, Facebook Live and Instagram. Through this work, we infer that the use of new technologies, as well as the implementation of teaching and learning with their help, with quality, requires planning and investments, which will not be possible in the very short term, as has been the case, for example, in this pandemic moment, and even though the knowledge developed with these resources can potentially be used for educational purposes so that we alert to the need that Brazil has for incentives for teacher training with new proposals for integration and not for substitution of classroom teaching and/or quality remote.
\end{abstract}

Keywords: Digital Technologies; Remote classes; Pandemic; Mathematics Teaching. 


\section{Introdução}

O mundo inteiro foi surpreendido pela pandemia do COVID-19, uma doença causada pelo coronavírus SARS-CoV-2, que por se tratar de um novo agente viral descoberto no final de 2019, ficou amplamente conhecido como novo coronavírus, o qual apresenta em seus infectados um quadro clínico que varia de infecções assintomáticas a quadros respiratórios graves que podem levar a morte. A Organização Mundial da Saúde (OMS) recomendou como principal medida de enfrentamento para a corrente pandemia, o distanciamento social ${ }^{3}$ até ser encontrada uma possível cura para a doença.

Com as medidas de distanciamento social, a Organização das Nações Unidas para Educação, Ciência e Cultura (UNESCO) estima que mais de um bilhão de discentes estão em casa por meses em todo o mundo em decorrência da pandemia. No Brasil como consequência do aumento de casos e a partir da recomendação da OMS, no mês de março de 2020 as atividades escolares presenciais em todos os níveis foram suspensas pelo Ministério da Educação (MEC), levando aproximadamente quase 53 milhões de discentes a ficarem sem aula.

Neste contexto, surge a seguinte problemática "como desenvolver atividades educacionais, em especial o ensino de Matemática, sem o retorno presencial das aulas?". Uma das alternativas encontradas por diversos países, incluindo o Brasil é a transferência das aulas para plataformas online (o ensino remoto) e a utilização das Tecnologias da Informação e Comunicação (TIC) e Tecnologias Digitais (TD), ambas comumente utilizadas na Educação à Distância.

No contexto brasileiro, acreditar que a simples implementação da transição do ensino presencial para o ensino remoto resolverá os problemas é uma grande ilusão, uma vez que mesmo nos deparando com um leque de possibilidades, estaremos diante de grandes desafios, como buscamos apresentar em parte no decorrer deste estudo, onde abordamos um pouco de ambas as vertentes tratando particularmente destas ligadas ao ensino de Matemática.

\footnotetext{
${ }^{3}$ Existem diferença entre distanciamento social, isolamento, quarentena e lockdown, a saber: o distanciamento social é a iniciativa voluntária de se distanciar das pessoas, mesmo não estando doente, para evitar o contato com infectados. Já isolamento, é uma medida não obrigatória que tem como objetivo separar as pessoas doentes, das pessoas não doentes, evitando desta forma a propagação do vírus; a quarentena, por sua vez, é uma medida administrativa mais ampla, feita pelas autoridades que restringe o acesso ou circulação de pessoas que foram ou podem ter sido expostas ao vírus. Quando essas medidas são insuficientes, existe, ainda, um nível mais restritivo de isolamento feito pelas autoridades, o bloqueio total ou lockdown, que é uma paralisação total dos fluxos e deslocamentos.
} 
De modo geral, queremos salientar que nossa intenção não é tentar contemplar todas as plataformas disponíveis e nem oferecer uma espécie de tutorial sobre os recursos e ferramentas apresentadas, mas sim destacar alguns dos desafios do uso de tecnologias e algumas das possibilidades existentes para utilização destas no contexto educacional durante a pandemia, e quem sabe, depois dela.

\section{Ensino remoto e Ensino a Distância}

Para desenvolvermos a discussão sobre nosso estudo, existe a necessidade de compreendermos que ensino remoto e ensino à distância não são a mesma coisa. $\mathrm{O}$ ensino remoto ou aula remota, no contexto que vivemos atualmente, é uma solução emergencial temporária com a finalidade da prosseguir com algumas atividades pedagógicas, buscando minimizar os impactos no processo de aprendizagem dos discentes, não se tratando de uma modalidade de ensino. Já o ensino à distância, tem sua estrutura e metodologia planejados a longo prazo para garantir o ensino na Educação à Distância (EAD) de qualidade, possuindo várias particularidades.

Segundo a atual legislação nacional, na Lei de Diretrizes e Bases da Educação Nacional (LDB) em nenhum momento aborda o termo ensino remoto, apenas menciona a Educação à Distância como modalidade de ensino, a qual é regulamentada pelo Ministério da Educação (MEC), que a caracteriza como modalidade de ensino em que todos os envolvidos se encontram separados fisicamente e temporalmente e, desse modo, utilizam a tecnologia para criar esse processo de aprendizagem. Assim, o ensino remoto apenas se assemelha a EAD no contexto do uso das tecnologias, mas os princípios que o embasam são do ensino presencial.

\section{As Tecnologias, as TIC e as TDIC}

Para apresentarmos nosso estudo, também existe a necessidade de diferenciarmos alguns termos segundo seus conceitos como: Tecnologias, Tecnologias da Informação e Comunicação (TIC) e as Tecnologias Digitais da Informação e Comunicação (TDIC).

A palavra tecnologia é de origem grega téchne (arte ou ofício) e logia (estudo). A tecnologia é uma produção basicamente humana, tendo em vista que o ser humano foi obrigado a produzir novos conhecimentos por estarem constantemente sendo desafiados por situações que se apresentavam cotidianamente desde a pré-história, assim produziu 
no decorrer de suas necessidades tecnologias como a roda, o arco, o lápis, o papel, a caneta, o rádio, a televisão, o computador, entre outras. "As tecnologias são tão antigas quanto a espécie humana. Na verdade, a engenhosidade humana, em todos os tempos, que deu origem às mais diferenciadas tecnologias” (KENSKI, 2013, p. 15).

A utilização do termo Tecnologias da Informação e Comunicação (TIC) se refere aos dispositivos eletrônicos e tecnológicos mais antigos, em que se incluem o rádio, a televisão, o jornal, mimeógrafo, e até as mais atuais como o computador, a internet, o tablet e smartphone os quais tem a finalidade de informar e comunicar.

Atualmente, embora se evite usar o termo Novas quando se fala de tecnologia, pesquisadores tem utilizado o termo Novas Tecnologias para se referir às Tecnologias Digitais (KENSKI, 1998) ou ainda de Tecnologias Digitais da Informação e Comunicação (TDIC) para designar os dispositivos mais atuais como o computador, o tablet, o smartphone e qualquer outro dispositivo que permita a navegação na internet (BARANAUSKAS; VALENTE, 2013) que funcionam por meio digital e não mais analógico.

Assim, utilizaremos os termos Tecnologias Digitais de Informação e Comunicação (TDIC) ou simplesmente Tecnologias Digitais, para nos referirmos aos dispositivos que serão utilizados para acesso as aulas e demais conteúdos digitais disponibilizados ou construídos para serem acessados através de navegação na internet por docentes e discentes de modo geral neste momento de pandemia.

Logo, ao abordarmos as Tecnologias Digitais e o seu atual significado em nossa sociedade, mais precisamente na escola e no ensino de Matemática no contexto da corrente pandemia, o qual é nosso objeto de análise, devemos esclarecer que as TDIC são compreendidas como um conjunto de equipamentos e aplicações tecnológicas que geralmente utilizam a internet e diferenciam-se das Tecnologias de Informação e Comunicação (TIC) também pela presença do termo digital.

O termo digital, deriva de dígito, do latim digitus, que significa dedo, de modo que ao ser inserido em tecnologias, quer dizer que temos acesso a milhares de informações ao simples toque dos dedos, mas não somente isso, também se refere ao tipo de recepção de sinal que é digital e não analógico, bem como tem seu significado ligado ao conjunto de tecnologias que permite, principalmente, a transformação de qualquer linguagem ou 
dado em números, neste caso em zeros e uns (0 e 1), o chamado sistema binário de representação, que é a linguagem que os dispositivos reconhecem.

\section{Tecnologias Digitais e a Formação de Professores de Matemática}

Para nós docentes, essa transição para o ensino remoto de uma forma não planejada traz grandes desafios, uma vez que boa parte dos professores brasileiros não se encontra, efetivamente, capacitada para desenvolver atividades que integram as tecnologias digitais ao processo de ensino e aprendizagem, seja por não estar inclusa no currículo das disciplinas estudadas na graduação, seja por falta de investimentos ou mesmo incentivos na formação continuada nas políticas educacionais.

Para que de fato se busque atingir a proposta do uso de tecnologias no ensino, há necessidade de formação contínua do professor, promovendo trocas de experiências e fortalecimento do conhecimento, reforçando que o professor será o mediador do processo de ensino e aprendizagem e os alunos protagonistas se apropriando do conhecimento.

A apropriação do conhecimento amplia as possibilidades de atuação, podendo transformar estas ferramentas e/ou objetos de estudos em instrumentos de contribuição recíproca entre professores/alunos por meio de troca de experiências, discussões e adequações de propostas, fomentando assim o senso crítico do aluno, desenvolvendo as habilidades e competências essenciais e almejadas.

Diante das mudanças advindas da utilização dos recursos de informática educativa no ensino e aprendizagem de Matemática no contexto escolar, os educadores vêm buscando o aperfeiçoamento por meio de formações que visem a utilização dos recursos tecnológicos nas práticas pedagógicas, porém, apenas isso não garante a efetividade do processo educacional, conforme afirma Papert (2008, p.70), "muito mais do que 'treinamento', é necessário que os professores desenvolvam a habilidade de beneficiaremse da presença dos computadores e de levarem este benefício para seus alunos”.

Nesta perspectiva, o papel do professor de Matemática, assim como os demais docentes, está diretamente ligado à busca de novos conhecimentos a partir de pesquisas, leituras e troca de informações e experiências com outros educadores, no sentido de catalisar informações de como dominar a utilização das tecnologias educacionais no processo de ensino e aprendizagem de Matemática, de modo que se torne um pesquisador 
permanente na busca de novos conhecimentos, em que consiga ao mesmo tempo ensinar e aprender.

Ao levarmos em consideração o arcabouço de informações existentes na sociedade da informação em que vivemos, ao professor de Matemática não cabe apenas transmitir os conhecimentos que possui, mas de mediar o ensino por meio dos recursos da informática em prol da contribuição efetiva do processo educacional, desse modo modificando sua postura em relação aos discentes em sala de aula e fora dela, no sentido de tratá-los como protagonistas responsáveis da aquisição do seu próprio conhecimento matemático. Reforçando a importância da mediação Camas (2013), afirma que:

[...] o uso das tecnologias digitais aumenta o número de informações disponíveis e novas formas de comunicação podem ser introduzidas no sistema escolar. Entretanto, a qualidade desta comunicação e a transposição das informações em conhecimento são dependentes da mediação feita pelo professor das metodologias dialogadas pelas instituições educacionais (professores, gestores, alunos e comunidades pertencentes à escola) na realização desta nova forma de fazer educação. (CAMAS, 2013, p.13)

Neste contexto, cabe ao professor de Matemática a criação de encaminhamentos pedagógicos que proporcionem mediação entre os conhecimentos desta disciplina e os recursos da informática educativa adequados existentes, oferecendo ao aluno a apropriação do conhecimento mediante diferentes formas como exploração, interação, pesquisa, comunicação por diferentes meios, troca de experiências, colaboração e reorganização das informações. Sendo assim, a mediação do professor em todo o processo imprescindível para a efetivação deste, tendo em vista que os recursos tecnológicos sozinhos, dissociados de um norte, e sem encaminhamentos com finalidades educacionais específicas, não ocasionarão um processo de ensino e aprendizagem de Matemática efetivo, como afirma Moran (2007, p. 12):

[...] há uma expectativa de que as novas tecnologias nos trarão soluções rápidas para o ensino. Sem dúvida as tecnologias nos permitem ampliar o conceito de aula, de espaço e tempo, de comunicação audiovisual, e estabelecer pontes novas entre o presencial e o virtual, entre o estarmos juntos e o estarmos conectados a distância. Mas, se ensinar dependesse só de tecnologias, já teríamos achado as melhores soluções há muito tempo. Elas são importantes, mas não resolvem as questões de fundo. Ensinar e aprender são os desafios maiores que enfrentamos em todas as épocas e particularmente agora em que estamos pressionados pela transição do modelo de gestão industrial para o da informação e do conhecimento. (MORAN, 2007, p.12) 
A utilização das tecnologias digitais esbarra em alguns entraves como as dificuldades na adaptação que muitos educadores de Matemática têm na utilização destes, e acabam por deixar de fazer uso destes recursos em suas práticas. Todavia, se vivemos em uma sociedade marcada pelo desenvolvimento tecnológico, logo a educação que possui um papel fundamental não deve estar a margem desse desenvolvimento, e assim o uso de recursos tecnológicos são indispensáveis pelo educador, cabendo a este a busca da apropriação do conhecimento para a utilização em sala de aula e fora dela.

Outra dificuldade pertinente ao uso das tecnologias nas práticas educacionais dos professores de Matemática, é o fato de que uma grande parte dos discentes não possuem contato com a informática em suas casas, o que segundo Coscarelli (2002), é um problema que pode ser sanado com a implantação de informática nas escolas:

\footnotetext{
Muitos professores argumentam que a informática não é realidade dos alunos. Esta é uma forte razão para se usar a informática na escola. Se em casa o aluno não vai ter acesso a esse equipamento, e consequentemente ao aprendizado que ele possibilita, é dever da escola viabilizar o acesso do aluno ao computador. O mundo profissional tem cobrado dos trabalhadores de todas as áreas conhecimento de informática, portanto, não dar esse conhecimento ao aluno é deixá-lo desde já fora do mercado de trabalho. (COSCARELLI, 2002, p.25)
}

De modo geral, o fato de que parte dos discentes não tenham acesso à informática fora da escola, é mais um motivo para que esta possibilite aos alunos o conhecimento de suas potencialidades, cabendo ao professor o papel de facilitador do processo educacional, no qual estimule o aluno a busca de uma aprendizagem significativa de forma dinâmica e efetiva, cabendo ao professor a escolha do software a ser utilizado para o desenvolvimento efetivo da atividade a ser trabalhada, uma vez que a partir dele estas serão desenvolvidas com os discentes com fins educacionais, como afirma Tajra (2001, p.74): “A utilização de um software está diretamente relacionada à capacidade de percepção do professor em relacionar a tecnologia à sua proposta educacional”.

O papel do professor de Matemática neste novo cenário educacional, continua e será sempre de fundamental e insubstituível importância, uma vez que, além de assumir o papel de mediador no processo de ensino e aprendizagem, traz consigo a sensibilidade de humanização de todo o processo, papel que nenhuma máquina por mais desenvolvida que seja, será capaz de assumir, mesmo com todo o avanço tecnológico existente, tendo em vista as características particulares existentes no processo educacional como a percepção das dificuldades e potencialidades de alunos distintos, tarefa na qual o 
professor de Matemática, com a visão humana consegue identificar. Gouvêa (1999) apud Lopes (2002) nos ensina que:

O professor será mais importante do que nunca, pois ele precisa se apropriar dessa tecnologia e introduzi-la na sala de aula, no seu dia-a-dia, da mesma forma que um professor, que um dia, introduziu o primeiro livro numa escola e teve de começar a lidar de modo diferente com o conhecimento. Continuaremos a ensinar e a aprender pela palavra, pelo gesto, pela emoção, pela afetividade, pelos textos lidos e escritos, pela televisão, mas agora também pelo computador, pela informação em tempo real, pela tela em camadas, em janelas que vão se aprofundando às nossas vistas [...]. (GOUVÊA, 1999, apud LOPES, 2002, p.4)

Portanto, o professor de Matemática, bem como os de todas as áreas do conhecimento, encontra-se diante do desafio de ter que se transformar em um profissional da modernidade, buscando desenvolver competências que um educador deve possuir na atualidade, consciente do seu papel na era informação e comunicação, conhecedor das possibilidades que as ferramentas tecnológicas ao seu redor possuem para criar novos modelos que satisfaçam o seu cliente, que neste caso é o aluno, neste contexto Moran (2007, p.70) afirma que "educar numa sociedade em mudanças rápidas e profundas nos obriga a reaprender a ensinar e a aprender [...], e a escola não pode ficar isolada da realidade que a cerca".

\section{Aulas remotas com Equidade}

Um dos grandes problemas da implementação de aulas remotas no Brasil é a equidade, um grande quantitativo de discentes vivem em uma situação de vulnerabilidade socioeconômica, não possuindo condições de acesso a cursos online, seja por falta de internet de qualidade, computadores, smartphones, ou ainda um espaço físico adequado para assistir às aulas. 
Figura 1 - Abismo na Educação.

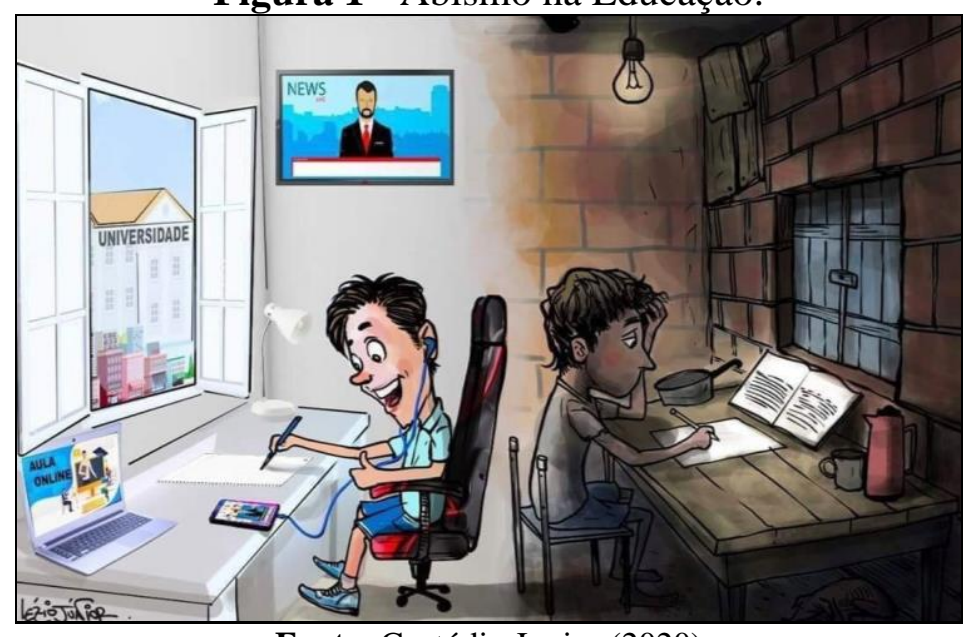

Fonte: Custódio Junior (2020)

Outro possível entrave, é que nem todos os discentes possuem o conhecimento de como utilizar as tecnologias digitais, bem como não possuem o suporte necessário para desenvolver tal conhecimento, nem apoio efetivo por parte de sua família na realização das tarefas que lhe forem apresentadas, e dependendo de como se der o desenvolvimento e a complexidade do que será utilizado como recurso, a desigualdade existente poderá aumentar ainda mais.

Para Borba e Penteado (2016), a inserção da utilização dos recursos tecnológicos é um direito e os alunos necessitam de ter conhecimentos tecnológicos compreendido como um processo de aquisição de capacidades cognitivas em que a Matemática tem sido vista como privilegiada em relação as tecnologias existentes e/ou presentes no mundo moderno tais como: jogos, calculadoras, materiais concretos, softwares entre outros recursos tecnológicos.

O discente no decorrer do processo de ensino e aprendizagem, e consequentemente construção do conhecimento, pode utilizar diversos meios e ferramentas para se desenvolver. No que condiz o ensino remoto, este discente tem que possuir potenciais para se adequar e familiarizar-se à aprendizagem individual, coletiva e colaborativa dentre todos os envolvidos nesse processo, o qual está diretamente ligado ao uso de novas tecnologias, as quais são fundamentais para a efetivação do processo em questão. 


\section{Desenvolvimento de atividades remotas}

Em atividades remotas os alunos não se encontram no mesmo espaço realizando as tarefas propostas, para isso utilizam plataformas virtuais. Quando as aulas são oferecidas em tempo real mediante uma plataforma de videoconferência como Zoom Meetings, Google Meet, Microsoft Teams, entre outras, dizemos que estas aulas são síncronas. Já quando o aluno utiliza uma plataforma como Moodle, Khan Academy ou Google Classroom, realizando tarefas ou assistindo a uma aula gravada anteriormente, dizemos estas aulas são assíncronas.

Como dito, as aulas presenciais estão suspensas desde março em escolas públicas e privadas da rede estadual e municipal de diversos estados brasileiros, e que esta suspensão também foi aderida pelas Instituições de Ensino Superior (IES). Porém, o MEC publicou a portaria de $n^{\circ} 343 / 2020$ que autoriza as instituições de educação superior integrante do sistema federal de ensino a utilização de meios e tecnologias digitais para a substituição temporária das aulas presenciais, e assim recomenda o setor não cancelar as atividades, mas sim fazer com que estas fossem realizadas forma remota pela internet, por meio de ambientes virtuais de aprendizagem (AVA) ou Sistema de Gestão de Aprendizagem (LMS, na sigla em inglês).

O que nos faz pensar sobre como a educação básica, que na maioria dos casos não conta com AVA ou LMS, ou mesmo outros seguimentos educacionais podem buscar desenvolver de alguma forma suas atividades de ensino e aprendizagem de maneira remota e assíncrona. Neste contexto, se apresenta como uma possível alternativa a utilização do Google Sala de Aula ou Google Classroom.

\section{Figura 2 - Google Classroom}

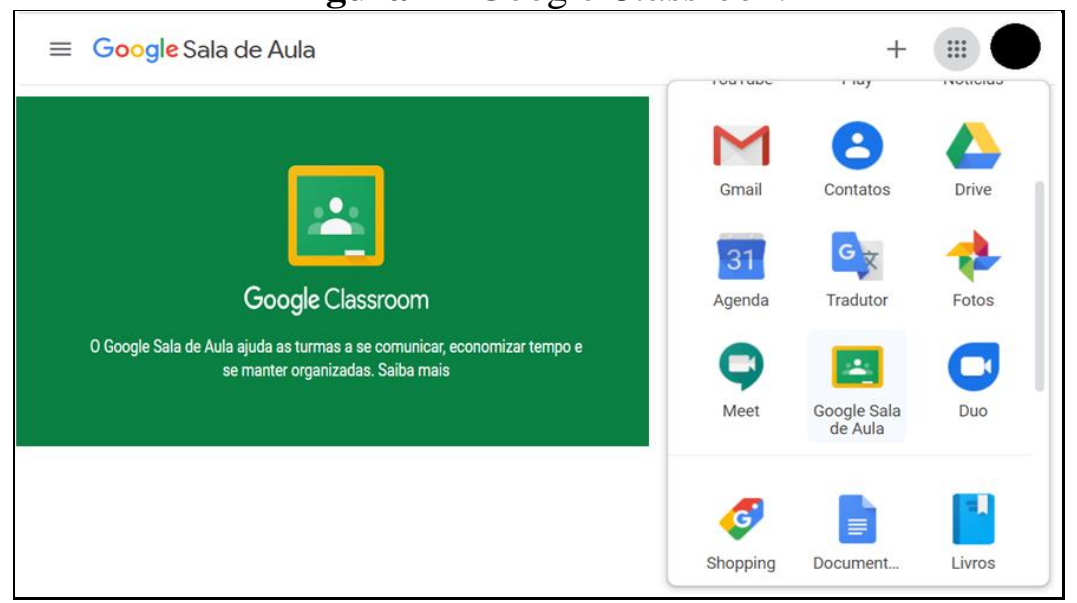

Fonte: Elaborado pelos autores (2020). 
O Google Classroom é um sistema de gerenciamento de conteúdo para escolas que procuram simplificar a criação, a distribuição e a avaliação de trabalhos. Ele é um recurso do Google Apps para a área de educação, sendo totalmente gratuito, necessitando apenas da existência de uma conta e-mail da Google, ou seja, um Gmail.

No Classroom temos a possibilidade de criar turmas e solicitar que os alunos entrem através de um código gerado para o acesso. Nesse sistema, o docente pode contar com três menus, que são: mural, atividades, pessoas e notas, os quais oferecem vários recursos para o desenvolvimento de atividades educacionais.

O menu mural oferece a possibilidade de inserir e compartilhar avisos ou outras informações utilizando materiais do Google Drive, links de materiais ou sites, anexação de arquivos e vídeos do YouTube, e ainda responder as postagens dos alunos. Em atividades podem ser postadas as tarefas que o professor deseja que os discentes realizem, bem como permite também a disponibilização de materiais, testes, perguntas e até a criação de tópicos, com a possibilidade de utilização dos mesmos recursos, que já citamos, disponibilizados no mural e também de documentos, apresentações, planilhas, desenhos e formulários.

No menu pessoas é disponibilizado o nome de todos os discentes participantes da turma, permitindo ainda convidar mais professores e alunos para integrar por meio do endereço de e-mail. No menu notas é onde serão disponibilizados os resultados da avaliação das atividades desenvolvidas pelos discentes atribuídas pelo professor.

\section{A interação por meio de Plataformas}

Como alternativa para compartilhamento de conteúdo professores e alunos acabam encontrando soluções utilizando ferramentas como e-mail, listas de WhatsApp e grupos em redes sociais.

Outra opção para o desenvolvimento de aulas por áudio e vídeo de maneira síncrona, a partir de plataformas como Zoom Meetings, Google Meet, Microsoft Teams, YouTube e até Facebook Live, bem como o Instagram, entre outros. A seguir apresentamos, uma pequena descrição superficial sobre estas plataformas.

O Zoom é um software de videoconferência que pode ser utilizada para reuniões online, bate-papo ao vivo e aulas online. Com este recurso, na versão gratuita, é possível realizar reuniões online um a um ou com até cem pessoas ao mesmo tempo com duração 
máxima de 40 minutos, utilizando computadores, tablets e smartphones. Para melhor utilizar o Zoom, é interessante possuir webcam e microfone, oferecendo-se desse modo, maior flexibilidade e qualidade nas interações digitais por meio deste.

Ao realizar o download e posterior instalação do aplicativo Zoom no seu computador ou telefone e participar de qualquer reunião com um ID de reunião que lhe for fornecido. Vale ressaltar que em qualquer momento você pode optar por desativar áudio e/ou vídeo antes e ingressar nas reuniões. Existe também como opção a criação de conta gratuita do Zoom, vinculando sua conta do Google e, a partir daí, criar uma nova reunião, agendar uma, participar de uma reunião, compartilhar uma tela, adicionar contatos e assim por diante.

Um outro recurso muito importante é o de gravação da videoconferência em curso, isto é, o Zoom permite gravar a transmissão que está ocorrendo, oferecendo também a opções de pausar a gravação e posteriormente dar prosseguimento a esta. Este recurso permite ao docente gravar sua aula remota e posteriormente disponibiliza-la para a turma no Google Sala de Aula por meio de upload do computador, para que os discentes baixem posteriormente, ou ainda disponibilizar em uma conta no YouTube e assim disponibilizando o link para esta no Mural, sem a necessidade de baixá-la.

Figura 3 - Zoom Meetings

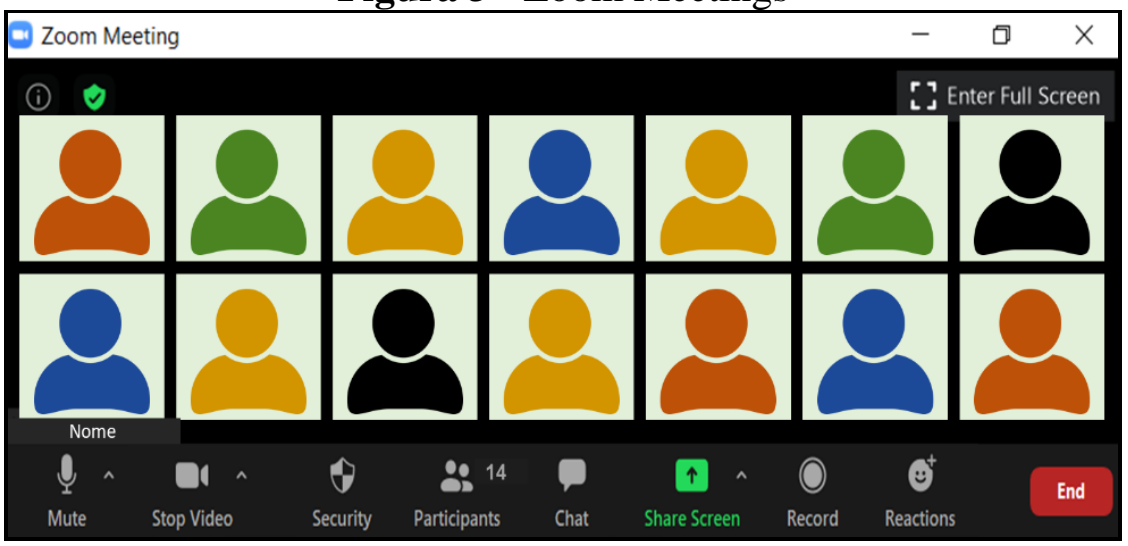

Fonte: Elaborado pelos autores (2020).

Um diferencial do Zoom, é que para acessar uma reunião o estudante não precisa ter uma conta cadastrada o que facilita bastante a interação entre professor e os usuários. É um software leve, de fácil manuseio e que oferece versão gratuita por tempo indeterminado. Em sua versão gratuita recebe até 100 participantes, em grupo com no máximo 40 minutos de duração, e na sua versão paga admite de 100 a 300 participantes 
dependendo do plano adquirido, e ainda com duração ilimitada para reuniões em grupo, entre outros serviços.

Já o Google Meet é o serviço de comunicação por videochamada da Google, que anteriormente era um serviço pago. Porém, atualmente em meio a pandemia do coronavírus, está sendo disponibilizado gratuitamente a quem tiver uma conta de e-mail da Google, de modo que não existe a necessidade de instalação para sua utilização em computadores, já em smartphones e tablets recomenda-se a instalação do aplicativo para o seu uso.

Figura 4 - Gmail e Google Meet

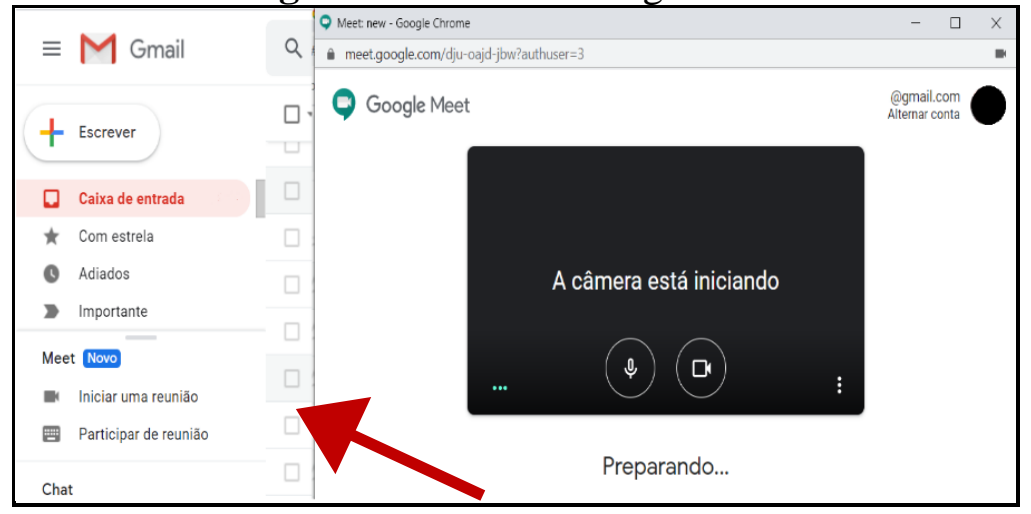

Fonte: Elaborado pelos autores (2020).

Segundo informações contidas no site da Google, o Google Meet é um dos serviços que substituem a versão anterior do Google Hangouts, o qual ainda está disponível livremente, nele a comunicação ocorre através de mensagens instantâneas, bem como áudio, vídeo e compartilhamento de arquivos e fotos, como no WhatsApp, Telegram, Messenger e outros.

A Google, também informa em seu site, que está sendo disponibilizado até 30 de setembro de 2020, para todos os clientes cadastrados no G Suite (serviços da Google) acesso gratuito a recursos avançados de videoconferência do Google Meet, como reuniões maiores (até 250 participantes), transmissão ao vivo e gravação. Após esse período, a disponibilidade dos recursos do Google Meet será determinada pelo contrato de licença do G Suite do cliente, isto é, a partir de um cadastro e posterior compra de licença. No entanto, as reuniões gravadas permanecerão no Drive do proprietário. É importante ressaltar que em contas institucionais todos os recursos estão disponíveis. O usuário também tem a possibilidade de instalar algumas extensões ao Google e ter mais alguns recursos como chamada, por exemplo. 
Para quem tem apenas conta de e-mail da Google, durante a execução de uma videoconferência alguns serviços não são disponibilizados como a gravação. No caso do usuário ter uma conta G Suite e não apenas e-mail da Google, assim como no Zoom, poderemos disponibilizar a partir da videoconferência, o vídeo gravado na Sala de Aula do Google, mediante upload ou ainda por meio do link, caso tenhamos postado em outras plataformas.

O Microsoft Teams é uma plataforma de comunicação e colaboração da empresa Microsoft, que oferece vários recursos como bate-papo, videoconferências, armazenamento de arquivos, o qual inclui o desenvolvimento da produção colaborativa de arquivos, e ainda é integrado com o pacote de serviços e aplicações do Office 365, que é a versão online de aplicativos para escritório/produtividade Microsoft Office (Word, Excel, PowerPoint, entre outros), porém também possui extensões para a utilização de produtos que não pertencem a Microsoft.

Para sua utilização é necessária uma conta Microsoft, isto é, um e-mail pertencente a empresa, podendo ser Hotmail ou Outlook. Assim como as demais plataformas apresentadas permite a realização de reuniões online, mas com o diferencial de oferecer uma plataforma com vários recursos de forma integrada para o desenvolvimento de atividades, como realizar reuniões através de videoconferência de dentro da plataforma.

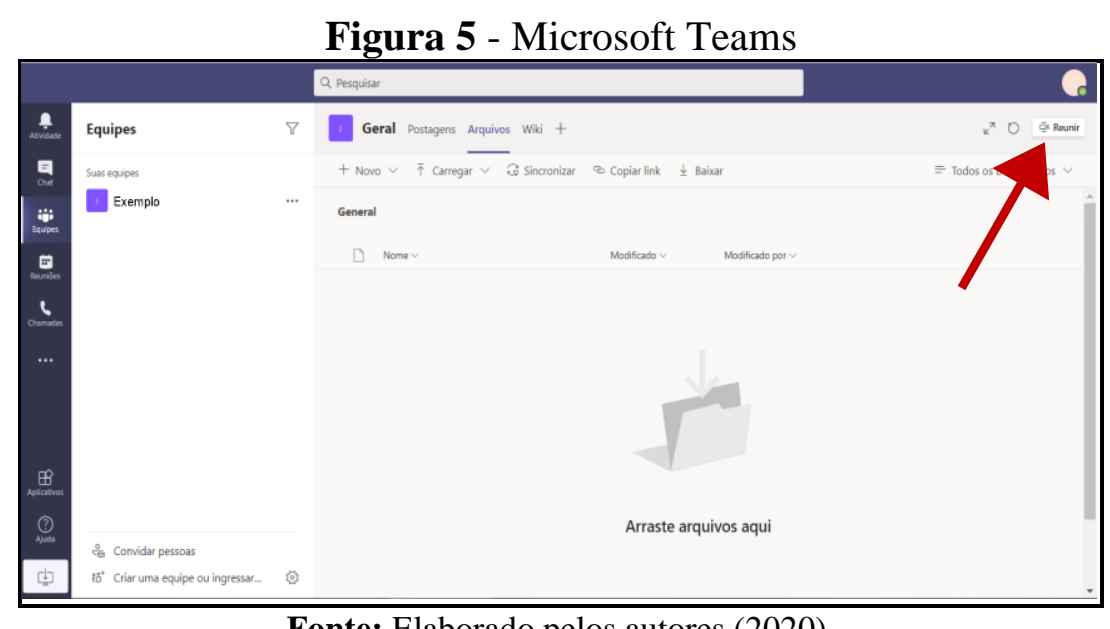

Fonte: Elaborado pelos autores (2020).

Como as outras plataformas apresentadas, o Teams tem sua versão paga e gratuita, oferecendo nesta última recursos mais limitados como a impossibilidade de gravação da reunião, porém é possível reunir até 250 participantes sem limite de tempo nas sessões, 
sendo um diferencial das outras plataformas e ainda permite 300 membros cadastrados por equipe.

Como alternativa para gravar as videoconferências ou mesmo aulas para serem disponibilizadas, podemos utilizar softwares adicionais que gravem o que está sendo exibido na tela do computador com a opção de gravação de áudio e vídeo, como o oCam ${ }^{4}$, ou ainda OBS Studio ${ }^{5}$ que oferece mais funcionalidades. Assim, independentemente da plataforma ou do tipo de apresentação, se vamos gravar em tempo real uma aula remota, ou gravar para disponibilizar posteriormente podemos utilizar outros recursos.

O YouTube, o Facebook e o Instagram permitem a transmissão de vídeos gravados ou em tempo real (as chamadas Lives), sendo meios de acessos a conteúdos que podem ser utilizados durante as aulas ou mesmo serem aulas já gravadas disponibilizadas para os discentes, mas para o acesso é necessário a criação de conta em ambos os serviços. É importante destacarmos que estes recursos necessitam de direcionamento e foco uma vez que oferecem outros conteúdos que facilmente desviam das finalidades educacionais que podem ser propostas.

Não podemos deixar de citar os Drives e as Ferramentas do Google Docs, os quais também têm sido muito usados no contexto da pandemia para trabalhos compartilhados e cooperativos. Os Drives são serviço de armazenamento e sincronização de arquivos em nuvem $^{6}$, como exemplo temos: o Google Drive e o OneDrive, entre outros.

Já as Ferramentas do Google Docs ou Google Documentos funcionam de forma síncrona e assíncrona, isto é, online para acessar dados em nuvens e offline através de aplicativos de extensão instaladas diretamente do Google, assim ele permite aos usuários criar e editar documentos online ao mesmo tempo colaborando em tempo real com outros usuários, suas ferramentas possuem compatibilidade com recursos do OpenOffice.org/BrOffice.org, KOffice e Microsoft Office, possuindo atualmente processador de texto, editor de apresentações, editor de planilhas e editor de formulários.

\footnotetext{
${ }^{4} \mathrm{O}$ oCam está disponível para download em: <https://ohsoft.net/eng/ocam/download.php?cate=1002 $>$. E seu tutorial pode ser encontrado em: <https://ohsoft.net/eng/ocam/tutorial/tutorial001.php?cate=1002 >.

${ }^{5}$ O OBS Studio está disponível para download em: $<$ https://obsproject.com/pt-br/download $>$. E seu tutorial pode ser encontrado em: <https://obsproject.com/docs/>.

${ }^{6} \mathrm{O}$ termo geralmente é usado para descrever centros de dados disponíveis para muitos utilizadores pela Internet, ou seja, armazenamento de dados que podem ser compartilhados.
} 


\section{Uma proposta para o ensino de Matemática}

Existem muitos canais e sites que disponibilizam aulas de Matemática, os quais podem ser indicados por professores para que seus discentes assistam, de modo a terem contato com os conteúdos. Mas, tratando de professores que gostariam de desenvolver seus próprios conteúdos e posteriormente disponibiliza-los online, bem como desenvolver atividades e manter contato com seus discentes utilizando o que apresentamos até aqui, e que é o nosso objetivo, oferecemos a seguir uma proposta de como desenvolver um conteúdo matemático e como exemplo tomamos o conteúdo de Poliedros.

Inicialmente, o professor deverá realizar o planejamento do que será utilizado na sala de aula referente ao conteúdo de Poliedros a ser disponibilizado e quando pretenderá realizar a aula remota.

Posteriormente, o professor e os discentes devem possuir ou criar uma conta de email na Google, isto é, um Gmail, para desenvolver as atividades, o professor para criar a turma e os discentes para serem adicionados nesta.

Indicamos que o docente deixe o e-mail criado para o desenvolvimento exclusivo com suas turmas, isto é, somente para desenvolver atividades educacionais, e a partir deste entrar no Google Sala de Aula, criar sua turma e realizar o upload (enviar do computador para a plataforma) dos arquivos que deverão ser disponibilizados para esta no menu Atividades, isto é, conteúdos e tarefas com prazos estipulados (tarefas assíncronas).

O professor deve possuir o contato de e-mail dos discentes para poder adicionálos na sala de aula no menu Pessoas, de modo a terem acesso aos conteúdos e atividades, também pode ser disponibilizado o código da turma para os discentes por outros meios, mas para nossa finalidade, recomendamos adicionar previamente por endereço de e-mail os discentes participantes para efeito de controle.

Com todos os discentes adicionados, será escolhida a plataforma de videoconferência para a execução da aula remota sobre Poliedros, que pode ser o Zoom Meetings, o Microsoft Teams, ou ainda o Google Meet, os quais oferecem o serviço gratuito com funcionalidades limitadas e na versão paga, por sua vez com todas as funcionalidades, ambos oferecem como recurso copiar link da transmissão ou ainda do código de acesso, os quais devem ser disponibilizados no Mural da turma, bem como 
enviados para o endereço de e-mail dos discentes minutos antes da transmissão, ou ainda antecipadamente, caso o professor tenha agendado no serviço de calendário.

No caso do conteúdo de Poliedros, bem como em demais conteúdos, indicamos que o docente tenha preparado uma apresentação de slides para o desenvolvimento da aula, e que aproveite o momento de contato com as tecnologias digitais para desenvolver o caráter imagético da Matemática, explorando as visualizações possíveis, utilizando, por exemplo, construções em softwares de Geometria Dinâmica ${ }^{7}$ como o Poly e o Geogebra, apresentando-o aos seus discentes.

Figura 6 - Apresentação de Slides e GeoGebra no Zoom

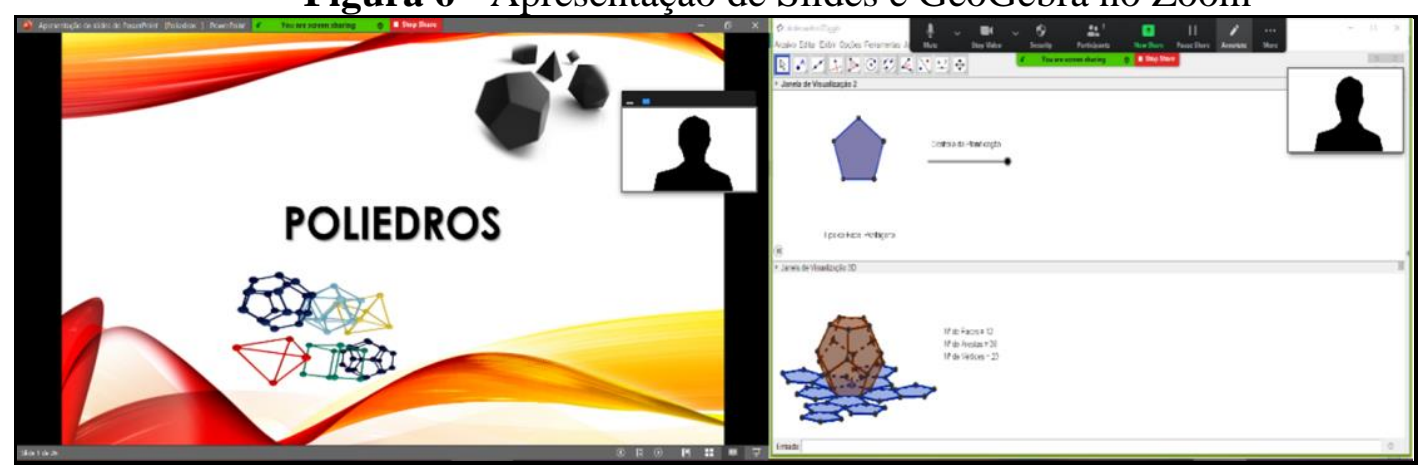

Fonte: Elaborado pelos autores (2020).

Com o uso do Geogebra, o estudo das propriedades dos Poliedros pode ser desenvolvido a partir da visualização. Ao tratarmos de visualização diferentes pesquisadores da área da Educação Matemática a definem com diferentes sentidos ligados à Matemática, à investigação científica, à Educação Matemática e também à psicologia. Para Dreyfus, (1991, p. 119): "visualização do ponto de vista da educação matemática inclui duas direções: a interpretação e compreensão de modelos visuais e a capacidade de traduzir em informação de imagens visuais o que é dado de forma simbólica".

As atividades propostas pelo professor devem envolver construções no software de GeoGebra pelos discentes, de modo que este possa ser um instrumento que contribuirá para o desenvolvimento, entre outras habilidades a de visualização, por meio da movimentação das figuras com o software, e assim promovendo maior exploração dos conceitos geométricos, para a aquisição e formalização destes.

\footnotetext{
${ }^{7}$ São ambientes virtuais voltados para o Ensino e Aprendizagem de Geometria de uma forma não estática como no quadro da sala de aula, ou seja, de uma forma dinâmica.
} 
Dentro deste contexto, a partir da visualização utilizando softwares de geometria dinâmica, juntamente com a apresentação de slides em uma aula remota utilizando Zoom ou Google Meet e disponibilizando materiais e o acompanhamento dos discentes em uma Turma criada no Google Sala de Aula, busca-se realizar o desenvolvimento do processo de ensino e aprendizagem de Matemática de uma maneira efetiva. Para tanto, reforçamos que o professor deverá conhecer previamente as ferramentas que pretenda explorar durante o desenvolvimento da aula remota, minimizando assim a possibilidade de problemas o uso destes recursos tecnológicos.

\section{Considerações Finais}

Como podemos observar o maior desafio de um ensino remoto recai sobre os educadores (professores), uma vez que sua ação carece de adaptação dos conteúdos, de novas dinâmicas em sala de aula, que vão além das aulas expositivas e dos métodos avaliativos anteriores, de modo a não prejudicar o processo de ensino e aprendizagem. Surge o desafio de como instigar os discentes durante a realização do novo processo.

Para o desenvolvimento de atividades educacionais, em especial o ensino de Matemática, sem o retorno presencial das aulas, apresentamos algumas possibilidades de expedientes visando o desenvolvimento das atividades escolares, mas precisamos reforçar que estas necessitam de recursos de internet, bem como certo conhecimento de suas ferramentas de modo a não nos deparáramos com problemas durante o desenvolvimento de atividades. E, assim, uma possível alternativa para minimização das chances de dificuldades é a participação de Webinários $^{8}$ com a temática ou ainda o aprendizado através de tutoriais disponíveis na internet por parte do docente e demais usuários interessados.

Não podemos esquecer, que mesmo após o término desta pandemia os conhecimentos desenvolvidos com esses expedientes poderão ser utilizados potencialmente para fins educacionais, mas em nenhum momento poderão substituir completamente o ensino presencial. Ainda que, não basta apenas criar um conteúdo e ir

\footnotetext{
${ }^{8}$ Webinários podem ser entendidos como seminários que ocorrem através da Web, isto é, redeconferências ou conferências online ou videoconferências com intuito educacional, no qual a comunicação é de apenas uma via, ou seja, somente o palestrante se expressa e as outras assistem (semelhante a vídeo aulas), onde a interação dos participantes é limitada ao chat, de modo que eles podem conversar entre si ou enviar perguntas ao palestrante.
} 
para frente de uma câmera e disponibilizar, ou mesmo apresentar em tempo real, para tanto é necessário planejamento e conhecimento das ferramentas.

Desse modo, podemos inferir que o uso de tecnologias digitais, bem como sua implementação nos processos de ensino e aprendizagem, requer planejamento e investimentos que não serão de disponibilidade imediata, como vem sendo proposto (prometido). Almejamos, que a situação emergencial que a pandemia nos colocou sirva de alerta para a necessidade de maiores incentivos à formação docente e da criação de novas propostas capazes de oferecer experiências de integração e não de substituição do ensino presencial e/ou remoto com qualidade.

Durante a finalização deste trabalho o MEC autorizou que atividades remotas contem na carga horária do ano letivo de 2020, demonstrando a relevância deste estudo e que se torna premente à necessidade de outros abordando temática semelhante.

\section{Referências}

BARANAUSKAS, M. C. C.; VALENTE, J. A. Tecnologias, Sociedade e Conhecimento. Revista Eletrônica Tecnologias, Sociedade e Conhecimento v.1, n.1. NIED/UNICAMP, 2013. Disponível em:

https://www.nied.unicamp.br/revista/index.php/tsc/article/download/118/96/>. Acesso: 02 jun. 2020.

BORBA, Marcelo; PENTEADO, Miriam G. Informática na Educação Matemática. 5ed. São Paulo: Autêntica, 2016. (Coleção Tendências em Educação Matemática).

CAMAS, Nuria; MANDAJA, Mônica; RIBEIRO, Renata; MENGALLI, Neli. Professor e cultura digital: reflexão teórica acerca dos novos desafios na ação formadora para nosso século, 2013. Disponível em 〈https://online.unisc.br/seer/index.php/reflex/article/view/3-834/3085 > . Acesso em 01 jun. 2020.

COSCARELLI, C. V. A informática na escola. Belo Horizonte FALE/UFMG, 2002. Disponível em < http://www.letras.ufmg.br/carlacoscarelli/publicacoes/Vivavoz.pdf $>$. Acesso em: 01 jun. 2020.

DREYFUS, T.; HADAS, N. Stereometrix: a learning tool for spatial geometry. In: ZIMMERMANN, W.; CUNNINGHAM, S. (Eds.). Visualization in teaching an learning mathematics. Washington, USA: Mathematical Association of America. p. 87-94, 1991.

KENSKI, V. M. Novas Tecnologias: o redimensionamento do espaço e do tempo e os impactos no trabalho docente. Revista Brasileira de Educação. nº 8, 58-71, 1997. 
Disponível em:

<http://anped.tempsite.ws/novo_portal/rbe/rbedigital/RBDE08/RBDE08_07_VANI_M

OREIRA_KENSKI.pdf > Acesso: 03 jun. 2020.

KENSKI, V. Educação e tecnologias. O novo ritmo da informação. Campinas: Papirus Editora. 2013.

LOPES, J. J. A introdução da informática no ambiente escolar. Instituto de Geociências e Ciências Exatas, dezembro, 2002. Disponível em:

http://www.clubedoprofessor.com.br/arti-gos/artigojunio.pdf >. Acesso em 04 jun. 2020.

MORAN, J. M. A educação que desejamos: Novos desafios e como chegar lá. São Paulo: Papirus, 2007.

PAPERT, Seymour. A Máquina das Crianças: repensando escola na era da informática. Porto Alegre: Artemed, 2008.

TAJRA, Sanmya Feitosa. Informática na educação. São Paulo: Érica, 2001.

UNESCO, United Nations Educational, Scientific and Cultural Organization.

Education: From disruption to recovery, 2020. Disponível em:

<https://en.unesco.org/covid19/educationres-ponse>. Acesso em: jun. 2020.

CUSTÓDIO JUNIOR, L. Crise mostra abismo na educação e pobres sofrerão mais se ENEM for mantido. Jornal Diário da Região, 2020. Disponível em:

$<$ https://pbs.twimg.com/media/EYZ9PEIX0AEPq03?format=jpg\&name=4096x4096>.

Acesso em: 25 ago. 2020.

Recebido em: 05 / 10 / 2020

Aprovado em: 10 / 12 / 2020 